\title{
Performance Assessment of a \\ Wide-Bandgap-Semiconductor Dual-Active-Bridge Converter for Electrical Vehicles
}

\author{
$1^{\text {st }}$ Nestor Berbel \\ Terrassa Industrial Electronics Group \\ Department of Electronic Engineering \\ Technical University of Catalonia \\ Terassa, Spain \\ Email: nestor.berbel-artal@upc.edu \\ $4^{\text {th }}$ Jose Luis Romeral \\ MCIA research center \\ Department of Electronic Engineering \\ Technical University of Catalonia \\ Terassa, Spain \\ Email: luis.romeral@upc.edu
}

\author{
$2^{\text {nd }}$ Gabriel J. Capella \\ Terrassa Industrial Electronics Group \\ Department of Electronic Engineering \\ Technical University of Catalonia \\ Terassa, Spain \\ Email: gabriel.jose.capella@upc.edu
}

\author{
$3^{\text {rd }}$ Jordi Zaragoza \\ Terrassa Industrial Electronics Group \\ Department of Electronic Engineering \\ Technical University of Catalonia \\ Terassa, Spain \\ Email: jordi.zaragoza-bertomeu@upc.edu
}

\begin{abstract}
Dc-dc converters can be found in different kinds of electric vehicles (EVs). Their main function is to accommodate voltages and currents to the motor or other EV systems requirements. The use of wide-bandgap (WBG) devices can improve the efficiency of silicon-based power converters, qualifying also for higher switching frequencies. In this article the features of a dual active bridge (DAB) converter are studied. The high voltage side of the DAB is implemented with Silicon Carbide (SiC) MOSFETs. For the low voltage side two types of devices are used: either Gallium Nitride (GaN) enhancement high-electronmobility transistors (e-HEMTs) or SiC MOSFETs. The influence of switching frequency and output power on the efficiency are evaluated. The parallel connection of GaN devices is proposed to overcome the device current limits and thus increase the overall DAB converter output power. A feedback controller has been designed to reduce the effects on the output voltage of load changes. The DAB converter evaluation has been realized by using MATLAB/Simulink and PLECS software.
\end{abstract}

Index Terms-DAB converter, Gallium Nitride (GaN), Silicon Carbide (SiC), losses, PLECS, power electronics, electric vehicle (EV)

\section{INTRODUCTION}

The growing popularity of electric vehicles (EVs), hybrid electric vehicles (HEVs), and pluggable hybrid electric vehicles (PHEV) is attributed to the wish of reducing global greenhouse emissions [1] and to vehicle performance improvements [2]. Inside the EVs, a full electric powertrain can be found, which is usually formed by an on-board charger (OBC), a high-voltage battery pack, and a motor-drive inverter [3], as can be seen in Fig. 1. The OBC converts ac energy from the electrical grid into dc energy which is required to recharge the batteries. A two-stage OBC includes a power factor correction (PFC) converter and an dc-dc converter 978-1-7281-9023-5/21/\$31.00 @ 2021 IEEE

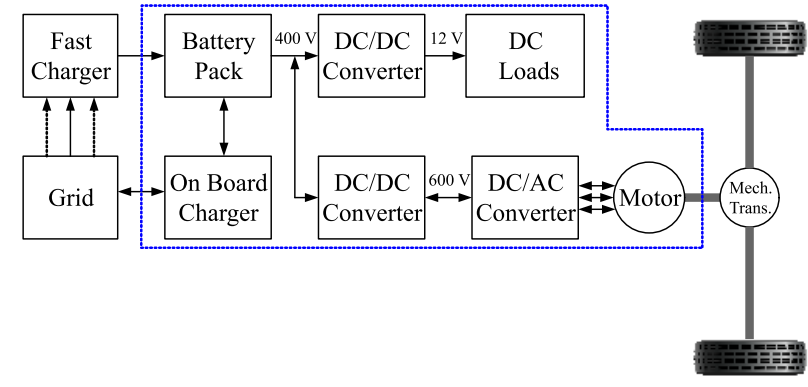

Fig. 1. Powertrain in an electrical vehicle.

with galvanic isolation, which connects the dc power supply to the dc circuitry onboard: charging stage, motor boosting inverter, energy storage, and ancillary loads. Research on PFC is relatively mature, with efficiencies that can reach over $98 \%$ [4]. The overall efficiency and power density of the dc system on board depends mainly on the design and the operation mode of the dc-dc converters. Dc-dc converters are used to adapt the voltage suppied by the battery pack (typically $200-300 \mathrm{~V}$ ) to the different voltages required by the motor drive (450-800V) and other vehicle systems (12-48V) and also to manage energy flows in the EV dc system, including energy storage [5]. The research goal is to improve the efficiency of these converters by developing next-generation topologies which should be more efficient, with a reduced part count, and be easily scalable. Therefore, a small-sized, reliable, light-weighted, controllable, scalable, and efficient dc-dc converter is likely to have a higher demand in automotive industries for BEV/PHEV and Automated Guided Vehicles (AGV) powertrains.

Multiphase, multiport, or multi-device boost converter 
topologies, which connect multiple electric sources using the parallel connection of switching converters can bring a solution when multiple input sources are required to drive different types of loads [6], while they qualify for bidirectional power flow and power recovering during regenerative braking, thus improving effectiveness and functionality. Additionally, in order to reduce the overall weight of the converter, nonisolated interleaved $\mathrm{dc} / \mathrm{dc}$ converters can be used to avoid the use of transformers. Isolated and non-isolated multi-phase interleaved converters are chosen for vehicular applications due to their capability of archiving a good performance of the electric sources with low voltage ripple. These converter topologies can minimize input current and output voltage ripple without increasing the size of passive components, qualifying for the use of higher switching frequencies, thus improving the overall efficiency and reliability of the system [5]. However, these topologies have stability problems as they are sensitive to load changes.

If galvanic isolation is needed between the source and the load, dual active bridge (DAB) converters can also be selected for EVs [7]. DAB phase-shift control can be adapted to a wide output voltage range with a fixed switching frequency, but the standard full-bridge PWM converter involves large reactive power circulation and cannot achieve soft switching under a light load. A phase-shifte full-bridge converter control is widely used for dc/dc convertes due to its several advantages [8]. However, there are some problems associated to the technology, such as significant conduction losses due to the circulating current during the freewheeling interval, and the voltage overshoots across the full-bridge rectifier on the secondary side, which increase significantly when the output voltage is high. Besides, when the output voltage is very high and the range of the output voltage is very wide too, a large inductance is required to reduce the current ripple. In order to reduce such drawbacks in conventional phase-shifte full-bridge (PSFB) converters, active clamp circuits [9] or modifications in the conduction angle for both primary and secondary bridges have been implemented [10].

DAB converters provide a higher overall power density when compared to systems including independent converters, which are widely implemented in the state-of-the-art converters for the EV [11].

Most of the dc/dc converters implemented in the powertrains of HEVs and PHEVs these days, are primarily based on the use of silicon transistors. This fact sets a limit to their efficiency $(92-93 \%)$, to the switching frequency $(30 \mathrm{kHz})$ and to the converter power density (1-15 kW/l) [12]. In contrast, the use of wide-bandgap devices (WBG) allows converters to operate at higher frequencies and temperatures, when compared to silicon based ones. Futhermore, WBG semiconductors have brought about significant increases in the converter power density, exceeding $15 \mathrm{~kW} / \mathrm{cm}^{3}$, and also to the converter efficiency, while ensuring a better manufacturability at a minimal cost [13]. Additionally, Gallium Nitride (GaN) enhancement high-electron-mobility transistors (e-HEMT) can be connected in parallel in order to further increase the rated power of the

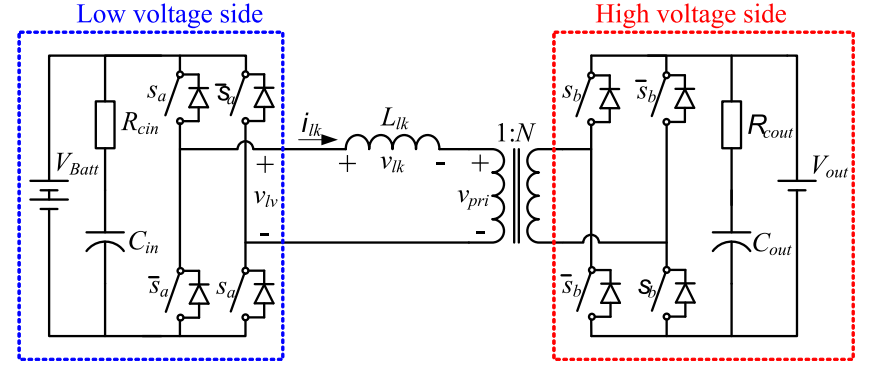

Fig. 2. Scheme of the DAB converter.

converter [14].

In this paper, the design of a high-power output, high-power density DAB converter suitable for its use in EVs is presented. Two possible solutions have been studied and compared. In the first option, the DAB is implemented only with SiC MOSFET transistors, whereas in the second one, one of the bridges is implemented with GaN e-HEMT and the other is implemented with SiC MOSFETs. The total power losses of the converter, for several switching frequencies and under different operating conditions have been analyzed for both solutions. Also, a feedback control has been designed to impose the desired output voltage, and to minimize the disturbances produced by sudden changes of the output load.

The rest of the paper is organized as follows: in Section II the DAB converter steady-state operation and its modulation technique are explained. In this section, a hardware design is proposed in order to implement the DAB converter with WBG devices. The section concludes with the design of a feedback controller to regulate its output voltage. The simulation model and the comparison of the results are described in Section III and the paper conclusions are drawn in Section IV.

\section{DAB CONVERTER}

The $\mathrm{DAB}$ converter is a bidirectional power converter, which can work with a high voltage conversion ratio while achieving high efficiency, with the added benefit of providing galvanic isolation. This power converter is part of the EV powertrain, as illustrated in Fig. 2. In this section, both the design method and the implemented modulation technique are described.

\section{A. DAB steady-state analysis}

The scheme of the DAB converter is depicted in Fig. 2 . The low-voltage side (LVS) of the DAB converter is powered by a high voltage battery $\left(V_{\text {Batt }}\right)$. This LVS converter drives the primary winding of the high-frequency transformer (HFT). $V_{o}$ is the load voltage at the high-voltage side (HVS) of the DAB. The full-bridge structure of both LVS and HVS can be implemented by means of BJT, IGBT, MOSFET or FET transistors. Each full-bridge can operate as either an inverter or a rectifier depending on the power flow. When the power flows from LVS to HVS, the LVS full-bridge works as an inverter whereas the HVS full bridge works as a rectifier. When power flows the other way around, both full-bridges swap their roles. 


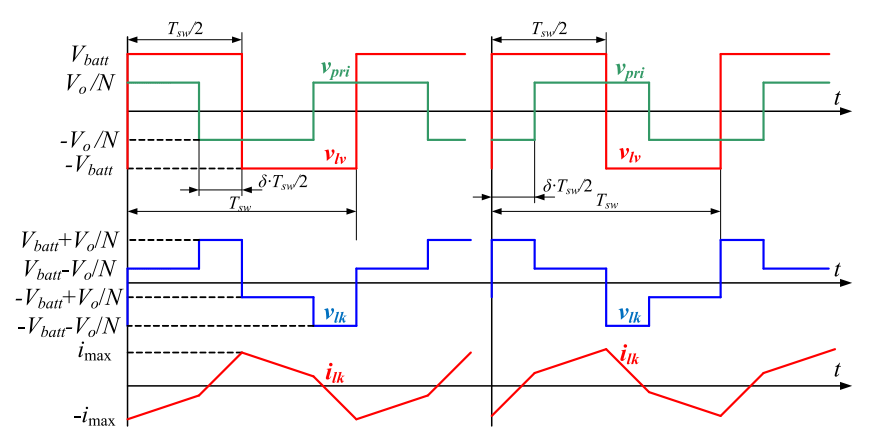

(a)

(b)

Fig. 3. Power transfer in a DAB converter: (a) High-voltage to Low-voltage power transfer, and (b) Low-voltage to High-voltage power transfer.

The HFT provides both galvanic isolation and voltage gain between the transformer windings, $N$ being the ratio of the secondary to primary winding voltages of the transformer:

$$
N=\frac{V_{\text {secondary }}}{V_{\text {primary }}}
$$

The leakage inductance $\left(L_{l k}\right)$ is the inductive component concerning the HFT to be considered as a result of the imperfect magnetic coupling between both windings. The phase shift $\delta \cdot \pi$ between the primary and secondary voltage waveforms determines the power flow direction. As depicted in Fig. 3(a), the power flows from the HVS to the LVS provided that the $\delta$ parameter has a negative value. Contrarily, the power flows in the opposite direction when $\delta$ has a positive value, as illustrated in Fig. 3(b).

On a steady-state, the DAB converter is equivalent to two high-frequency voltage sources connected to both sides of the leakage inductor, as can be seen in Fig. 2. The voltage applied to the inductor, $v_{l k}$, is plotted in blue in Fig. 3 . It is the result of subtracting the output voltages of the LVS and the HVS and dividing it by the transformer ratio $N$. The current in the leakage inductor $i_{l k}$ is determined by (2). The current flowing through the inductor is plotted in red in the lower part of Fig. 3(a), when power flows from HVS to LVS, and in Fig. 3(b) when it flows in the opposite direction.

$$
i_{L_{l k}}=\frac{1}{L_{l k}} \cdot \int v_{l k}(t) \cdot d t
$$

In [15], a Fourier analysis for the LVS, concerning $V_{l v}$ and $I_{L_{l k}}$ (see Fig. 2) is presented. The average value of the power that flows through the leakage inductor is calculated by multiplying both signals, and integrating the result for a switching period:

$$
P_{o}=\frac{1}{T_{s w}} \cdot \int_{0}^{T_{s w}} v_{l v}(t) \cdot i_{L_{l k}}(t) \cdot d t,
$$

which, once computed, leads to

$$
P_{o}=\frac{8 \cdot V_{B a t t} \cdot\left(\frac{V_{o}}{N}\right)}{2 \cdot \pi^{3} \cdot f_{s w} \cdot L_{l k}} \cdot \sin (\delta \cdot \pi),
$$

$f_{s w}$ being the switching frequency.
Considering that the power converter is loss-less, the input power must be equal to the output power. Therefore, modeling the load of the converter as a resistor, $R_{L}$, the output voltage of the converter would be

$$
V_{o}=\frac{8 \cdot V_{B a t t} \cdot R_{L}}{2 \cdot \pi^{3} \cdot f_{s w} \cdot L_{l k} \cdot N} \cdot \sin (\delta \cdot \pi) .
$$

As defined in (4), the output power depends on the leakage inductor $L_{l k}$, the load resistor $R_{L}$, the input voltage $V_{B a t t}$, and the switching frequency $f_{s w}$. Maximum power transfer is obtained for a $\delta$ value of \pm 0.5 , and the $\delta$ sign determines the power flow direction.

\section{B. DAB converter modulation technique}

Many modulation techniques have been presented to control the power flow. Single Phase-Shift (SPS) modulation technique is commonly prefered due to its simplicity [16], [17]. In SPS, each full-bridge control signal is a square signal with a $50 \%$ duty cycle, in order to ensure that the leakage-inductor current has a null mean value. The time delay between the control signals of LVS and HVS full-bridges is the main parameter that imposes the power flow direction on the DAB converter. The upper and the lower switches in the same leg of an inverter are switched on and off in a complementary manner. To prevent both transistors being switched on simultaneously, and thus short circuiting the power supply, a dead-time generator block is inserted, so both transistors in the same leg are switched off for a short period of time.

\section{DAB power device full-bridge considerations}

Due to the fact that a DAB power converter includes two full-bridges, the use of WBG devices may help improve its efficiency and power density. GaN e-HEMTs and SiC devices qualify for the power converter to switch at higher frequencies and allows for deadtime reduction [18]. They also help reduce conduction losses, in comparison with common $\mathrm{Si}$ devices. However, because of the high switching frequency, the use of WBG devices produces higher switching losses.

In this paper two approaches have been considered. One of them is to implement both full bridges in the DAB converter with $\mathrm{SiC}$ devices, whereas in the other one, only the LVS fullbridge is implemented with GaN e-HEMT devices. Due to the fact that LVS is supplied with a 300-500V battery, the use of GaN devices is a valid option, as long as the current flowing through the device does not reach its maximum rated value. If the maximum current on the LVS switches were greater than its maximum rated value, the parallel connection of single $\mathrm{GaN}$ e-HEMT devices would be way to overcome this issue. In that case, the number of GaN devices that should be connected in parallel would be determined by

$$
\text { Number of GaN devices }=\left\lceil\frac{\left.I_{L_{l k}}\right|_{\mathrm{Max}}}{\frac{I_{\mathrm{D} \mathrm{GaN}} \mid \mathrm{Max}}{k}}\right\rceil \text {, }
$$

where $\left.I_{L_{l k}}\right|_{\text {Max }}$ is the peak value of the current through the leakage inductor, $\left.I_{\mathrm{D} \mathrm{GaN}}\right|_{\mathrm{Max}}$ is the maximum rated current of 


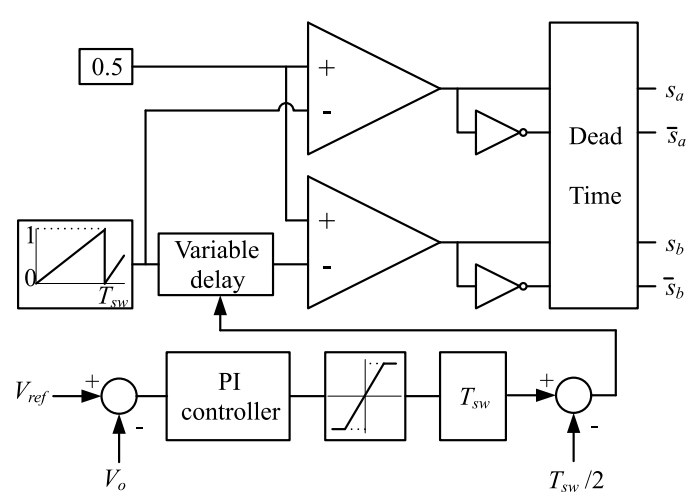

Fig. 4. Phase-shift control modulation scheme.

the GaN device, and $k$ is a safety factor. The maximum current through the leakage inductor is obtained by

$$
\left.I_{L_{l k}}\right|_{\operatorname{Max}}=\frac{V_{\text {Batt }}+(2 \cdot \delta-1) \cdot \frac{V_{o}}{N}}{4 \cdot L_{l k} \cdot f_{s w}} .
$$

On the HVS of the DAB, the use of SiC MOSFET is required as the devices should stand high voltages and high output currents. Besides, they switch at a high frequency. SiC devices have a low drain-to-source resistance, which leads to low conduction losses. On the contrary, their switching losses are higher when compared to those of Si devices.

\section{DAB feedback controller}

As described in (5), the DAB output voltage depends on the input voltage, the leakage inductor of the HFT, the HFT transformation ratio, and the output load, this one modeled as a resistor. Towards decreasing the susceptibility of the output voltage to these parameters, a voltage controller has been implemented, as can be seen in Fig. 4. The voltage reference is compared with the DAB output voltage, and the error signal is computed through a PI controller. The PI controller output is limited to \pm 0.25 because the maximum power transfer is obtained when $\delta$ is equal to \pm 0.5 . The PI output signal is then multiplied by $f_{s w}$ to determine the delay time. The PI controller has been tuned using the Ziegler-Nichols method.

\section{Simulation RESUlTS}

In this section the features of the DAB converter are assessed in two scenarios: when the LVS bridge is implemented with either $\mathrm{SiC}$ or when it is implemented with GaN switches, while the HVS bridge is in both cases implemented with $\mathrm{SiC}$ devices. The power converter has been modeled using MATLAB/Simulink and PLECS blockset. The battery input voltage can vary between $300 \mathrm{~V}$ and $450 \mathrm{~V}$, and the output voltage reference is set to $600 \mathrm{~V}$. The DAB converter is designed to deliver a rated power of $2.5 \mathrm{~kW}$. With these specifications, the required HFT transformation ratio is calculated as

$$
N=\frac{V_{o}}{\left.V_{\text {Batt }}\right|_{\min }} \cdot 1.25 .
$$

The selected transformation ratio, which corresponds to the quotient between the voltages of the secondary and the primary

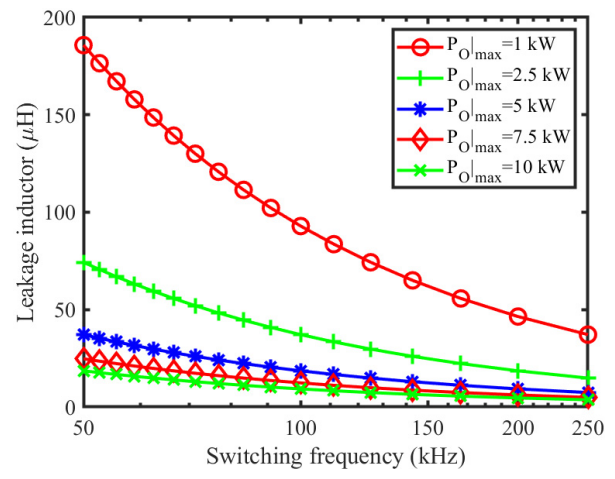

Fig. 5. Required leakage inductor vs. switching frequency.

windings, has been increased by a $25 \%$ factor in order to allow for some additional increase in the DAB output voltage, if necessary.

The leakage inductor required for a given switching frequency and output power is calculated according to (4). Fig. 5 depicts the leakage inductor value as a function of the rated output power, and the switching frequency. It can be seen that the higher the switching frequency, the lower the leakage inductor required.

For the implementation of the HVS bridge with $\mathrm{SiC}$ devices, the MOSFET module CCSM050M12CM2 has been used. This module can withstand a maximum drain-source voltage $\left(V_{D S}\right)$ of $1.2 \mathrm{kV}$ and a continuous maximum drain current $\left(I_{D}\right)$ of $59 \mathrm{~A}$, for a case temperature of $90^{\circ} \mathrm{C}$. This same module has been used to implement the LVS with SiC transistors. On the other hand, for the implementation of the LVS with GaN eHEMT transistors, GS66508T e-HEMTs have been used. The maximum $V_{D S}$ and $I_{D}$ for these transistors are $650 \mathrm{~V}$ and $30 \mathrm{~A}$, respectively. Conduction and switching losses have been calculated with the help of PLECS software. Manufacturers provide the PLECS thermal models, which includes conduction and switching power losses at several temperatures. Hence, this software helps compute power losses on the basis of the case temperature, gate resistor values, and the device current.

PLECS software enables the designer to consider electrical and thermal aspects together in the designing process, as it can provide information of the device junction temperatures $T_{j}$, and thus help compute conduction and switching power losses. The thermal equivalent circuit describes its physical structure in terms of heat flows from junction to ambient (see Fig. 6). The heatsink-to-ambient resistor $\left(R_{\Theta} \mathrm{SA}\right)$ models the heat sink. The case-to-sink resistor $\left(R_{\Theta \mathrm{CS}}\right)$ is the thermal resistance of the interface material, and the junction-to-case resistor $\left(R_{\Theta} \mathrm{JC}\right)$ is the thermal resistance of the device, supplied by the manufacturer. The simulation has taken into account the the thermal model to accurately determine the conduction and switching losses. Table I summarizes the values of the thermal model resistors.

Table II summarizes conduction and switching power loss results for both possible implementations. When the LVS is implemented with $\mathrm{GaN}$ transistors, lower losses are ob- 


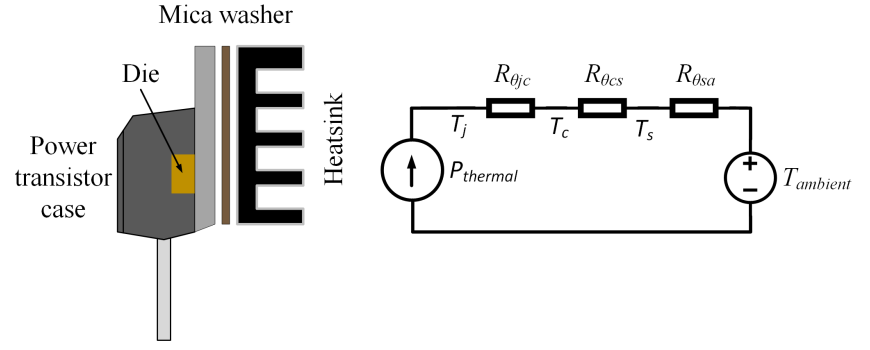

Fig. 6. Thermal model.

TABLE I

THERMAL MODEL RESISTORS

\begin{tabular}{c|c|c}
\hline Thermal resistor & $\mathrm{GaN}$ & $\mathrm{SiC}$ \\
\hline \hline$R_{\Theta A S}$ & $1{ }^{\circ} \mathrm{C} / \mathrm{W}$ & $1.22^{\circ} \mathrm{C} / \mathrm{W}$ \\
$R_{\Theta C S}$ & $0.2^{\circ} \mathrm{C} / \mathrm{W}$ & $0.2^{\circ} \mathrm{C} / \mathrm{W}$ \\
$R_{\Theta C J}$ & $1{ }^{\circ} \mathrm{C} / \mathrm{W}$ & $0.37^{\circ} \mathrm{C} / \mathrm{W}$ \\
\hline
\end{tabular}

TABLE II

CONDUCTION AND SWITCHING LOSSES

\begin{tabular}{c|c|c|c}
\hline DAB Converter Side & $f_{s w}$ & Conduction losses & Switching losses \\
\hline \hline LVS with & $50 \mathrm{kHz}$ & $13.82 \mathrm{~W}$ & $1.14 \mathrm{~W}$ \\
GaN devices & $250 \mathrm{kHz}$ & $17.79 \mathrm{~W}$ & $5.89 \mathrm{~W}$ \\
\hline LVS with & $50 \mathrm{kHz}$ & $35.19 \mathrm{~W}$ & $6.25 \mathrm{~W}$ \\
SiC devices & $250 \mathrm{kHz}$ & $35.91 \mathrm{~W}$ & $31.18 \mathrm{~W}$ \\
\hline HVS with & $50 \mathrm{kHz}$ & $12.97 \mathrm{~W}$ & $9.06 \mathrm{~W}$ \\
SiC devices & $250 \mathrm{kHz}$ & $13.10 \mathrm{~W}$ & $43.88 \mathrm{~W}$ \\
\hline
\end{tabular}

tained, as the SiC MOSFET drain-to-source resistance is lower $(25 \mathrm{~m} \Omega)$ in comparison with that of the GaN e-HEMTs FET $(50 \mathrm{~m} \Omega)$. Besides, because of the parallel connection of GaN devices and their lower junction temperature in steady-state conditions, the LVS implemented with GaN has yielded lower conduction losses.

According to their manufacturers, turn-on and turn-off switching energies in the SiC MOSFET are $1.1 \mathrm{~mJ}$ and $0.6 \mathrm{~mJ}$, respectively, whereas they are $47.5 \mu \mathrm{J}$ and $8 \mu \mathrm{J}$ in the $\mathrm{GaN}$ e-HEMT, also respectively. With lower turn-on and turnoff energy switching values, the converter will have fewer switching losses. Even though more GaN devices have been used on account of their parallel connection, the overall results obtained with $\mathrm{GaN}$ devices in terms of power losses are better.

In order to assess the total power loss reduction of the $\mathrm{GaN}$ $\mathrm{SiC}$ implementation with regards to the $\mathrm{SiC}-\mathrm{SiC}$ one, a powerloss ratio $(P L R)$ has been defined as

$$
P L R(\%)=\frac{T P L_{\mathrm{GaN}-\mathrm{SiC}}-T P L_{\mathrm{SiC}-\mathrm{SiC}}}{T P L_{\mathrm{SiC}-\mathrm{SiC}}} \cdot 100,
$$

where $T P L_{\mathrm{GaN}-\mathrm{SiC}}$ and $T P L_{\mathrm{SiC}-\mathrm{SiC}}$ are the overall power losses of both $\mathrm{GaN}-\mathrm{SiC}$ and $\mathrm{SiC}-\mathrm{SiC}$ implementations, respectively. The relationship of this ratio with the output power and the switching frequency is depicted in Fig. 7.

When GaN devices are used on the LVS, the total losses are $41 \%$ lower than those of the implementation with $\mathrm{SiC}$

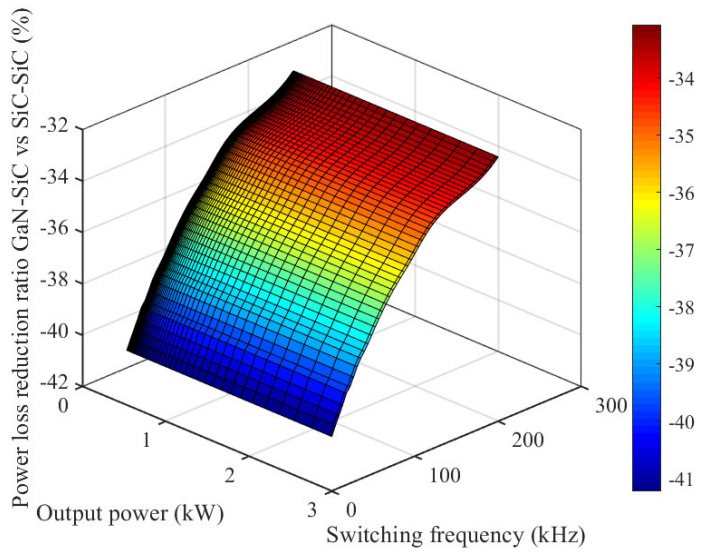

Fig. 7. Power-loss reduction ratio (PLR) in (\%).

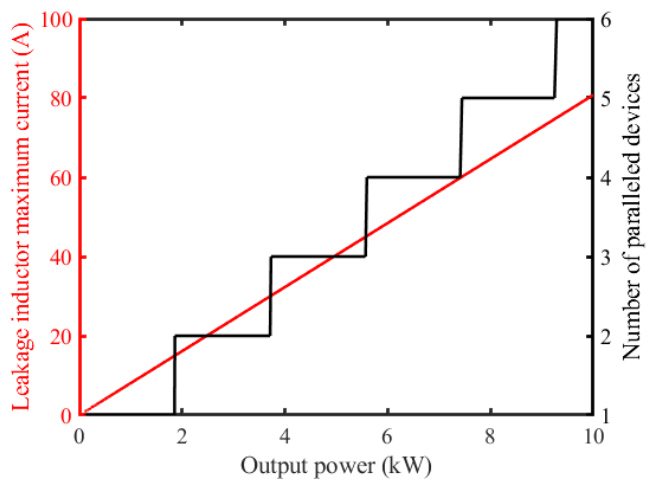

Fig. 8. Number of GaN devices in parallel

devices, at a switching frequency of $50 \mathrm{kHz}$. This loss reduction decreases at higher switching frequencies but still a $33 \%$ reduction is achieved at $250 \mathrm{kHz}$. However, maximum drain currents are smaller in $\mathrm{GaN}$ transistors than in SiC MOSFET devices.

In case the power of the converter is such that the current through the HFT leakage inductor is higher than the maximum drain current that a single $\mathrm{GaN}$ device can hold, several transistors can be connected in parallel to overcome such limitation. In order to determine the number of $\mathrm{GaN}$ devices to be connected in parallel for a given output power, the maximum inductor current is determined by (7) and the number of transistors by (6). The result for $V_{\text {Batt }}=450 \mathrm{~V}, V_{o}=600 \mathrm{~V}$ using GS66508T devices switching at $f_{s w}=250 \mathrm{kHz}$ has been plotted in Fig.8. For example, for an output power of $6 \mathrm{~kW}$, the maximum current on the primary side of the HFT is 48.63A, therefore 4 paralleled $\mathrm{GaN}$ devices would be required.

To validate the feedback controller design, the DAB converter has been simulated with different loads. The DAB converter output voltage should be $600 \mathrm{~V}$, regardless of the output current value. As can be seen in Fig. 9, the DAB converter output voltage quickly returns to its reference voltage when a sharp load change is applied at $t=1 \mathrm{~ms}$. 


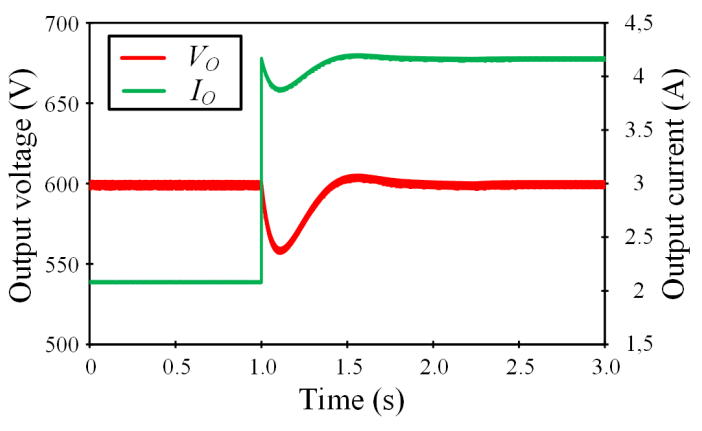

Fig. 9. Feedback Controller with load change

\section{CONCLUSION}

In this article, two possible implementations of a DAB converter as part of an EV powertrain have been compared. Switching and conduction losses have been considered for different powers and switching frequencies. The results of the study show that the DAB converter implemented with GaN eHEMTs and SiC MOSFET have less conduction and switching losses than the one implemented only with SiC-SiC MOSFET. The overall power loss reduction between both implementations ranges from $41 \%$ to $31 \%$, for switching frequencies of $50 \mathrm{kHz}$ and $250 \mathrm{kHz}$, respectively. GaN devices exhibit lower switching losses in comparison with SiC MOSFET but, on the other hand, their conduction losses are higher.

The use of GaN e-HEMTs devices has some drawbacks, like their relatively low maximum values of drain-to-source voltage and drain current. Due to such GaN limitations, these devices have been used only in the LVS of the DAB converter. In order to achieve higher output power levels, parallel connection of $\mathrm{GaN}$ devices has been utilized. To determine the number of $\mathrm{GaN}$ devices to connect in parallel the ratio between the peak current through the HFT leakage inductor and the GaN rated drain current, including an extra safety factor, have been considered.

The DAB converter output voltage depends on hardware parameters like the HFT transformation ratio, the HFT leakage inductor, input voltage, switching frequency, and output current values. The design of a feedback controller is proposed to decrease the susceptibility of the system. As simulation results demonstrate, with the help of a PI controller, its output can be regulated to $600 \mathrm{~V}$, which is the reference output voltage for the $\mathrm{DAB}$ converter.

\section{ACKNOWLEDGMENT}

This work was supported by the Industrial Doctorate Plan of the Secretaria d'Universitats i Recerca del Departament d'Empresa i Coneixement de la Generalitat de Catalunya, and the Ministerio de Ciencia, Innovación y Universidades of Spain within the project PID2019-111420RB-I00.

\section{REFERENCES}

[1] A. Khaligh and S. Dusmez, "Comprehensive topological analysis of conductive and inductive charging solutions for plug-in electric vehicles," IEEE Trans. on Veh. Technol., vol. 61, no. 8, pp. 3475-3489, Oct. 2012.

[2] A. Ahmad, M. S. Alam, and R. Chabaan, "A comprehensive review of wireless charging technologies for electric vehicles," IEEE Trans. on Transp. Electrification, vol. 4, no. 1, pp. 38-63, Mar. 2017.

[3] A. Khaligh and M. Dantonio, "Global trends in high-power on-board chargers for electric vehicles," IEEE Trans. on Veh. Technol., vol. 68, no. 4, pp. 3306-3324, Apr. 2019.

[4] A. Cavallo, B. Guida, and L. Rubino, "Boost full bridge bidirectional DC/DC converter for supervised aeronautical applications," International J. Aerosp. Eng., vol. 2014, Jan. 2014.

[5] S. Chakraborty, H.-N. Vu, M. M. Hasan, D.-D. Tran, M. E. Baghdadi, and O. Hegazy, "DC-DC converter topologies for electric vehicles, plugin hybrid electric vehicles and fast charging stations: State of the art and future trends," Energies, vol. 12, no. 8, p. 1569, Apr. 2019.

[6] S. Jwaid and M. Al-Chlaihawi, "Multiport converter in electrical vehicles - A review," Int. J. Sci. Res. Publ., vol. 6, May 2016.

[7] R. Rong and S. Zeljkovic, "A $2 \mathrm{~kW}, 100 \mathrm{kHz}$ high speed IGBT based HV-LV DC/DC converter for electric vehicle," in Proc. IEEE Conf. Expo Transport. Electrification Asia-Pacific (ITEC Asia-Pacific), Beijing, China, Aug. 31 - Sep. 3 2014, pp. 1-5.

[8] I. O. Lee, "Hybrid DC-DC converter with phase-shift or frequency modulation for NEV battery charger," IEEE Trans. Ind. Electron. vol. 63, no. 2, pp. 884-893, Feb. 2016.

[9] D. D. Tran, H. N. Vu, S. Yu, and W. Choi, "A novel soft-switching full-bridge converter with a combination of a secondary switch and a nondissipative snubber," IEEE Trans. Power Electron., vol. 33, no. 2, pp. 1440-1452, Feb. 2018.

[10] A. K. Bhattacharjee and I. Batarseh, "Optimum hybrid modulation for improvement of efficiency over wide operating range for triple-phaseshift dual-active-bridge converter," IEEE Trans. Power Electron., vol. 35, no. 5, pp. 4804-4818, May 2020.

[11] J. Schafer, D. Bortis, and J. W. Kolar, "Multi-port multi-cell DC/DC converter topology for electric vehicle's power distribution networks," in Proc. IEEE Workshop on Control and Modeling for Power Electron. (COMPEL), Stanford, CA, Jul. 9-12 2017, pp. 1-9.

[12] E. A. Jones, F. F. Wang, and D. Costinett, "Review of commercial GaN power devices and GaN-based converter design challenges," IEEE J. Emerg. Sel. Top. Power Electron., vol. 4, no. 3, pp. 707-719, Sep. 2016.

[13] O. Lucia, H. Sarnago, and J. M. Burdio, "Design of power converters for induction heating applications taking advantage of wide-bandgap semiconductors," Compel: Int. J. Comput. Math. Electr. Electron. Eng., vol. 36, pp. 483-488, Mar. 2017.

[14] J. L. Lu and D. Chen, "Paralleling GaN E-HEMTs in 10kW-100kW systems," in IEEE Applied Power Electron. Conf. Exposition (APEC), Tampa, FL, Mar. 26-30 2017, pp. 3049-3056.

[15] B. Zhao, Q. Song, W. Liu, G. Liu, and Y. Zhao, "Universal highfrequency-link characterization and practical fundamental-optimal strategy for dual-active-bridge DC-DC converter under PWM plus phaseshift control," IEEE Trans. Power Electron., vol. 30, no. 12, pp. 64886494, Dec. 2015.

[16] B. Zhao, Q. Song, W. Liu, and Y. Sun, "Overview of dual-active-bridge isolated bidirectional DC-DC converter for high-frequency-link powerconversion system," IEEE Trans. Power Electron., vol. 29, no. 8, pp. 4091-4106, Aug. 2014.

[17] F. Yazdani and M. Zolghadri, "Design of dual active bridge isolated bidirectional DC converter based on current stress optimization," in Power Electron. Drive Systems and Technol. Conf. (PEDSTC), Mashhad, Iran, Feb. 14-16 2017, pp. 247-252.

[18] Q. Yan and X. Yuan, "A double-modulation-wave PWM for dead-timeeffect elimination and synchronous rectification in SiC-device-based high-switching-frequency converters," IEEE Trans. Power Electron., vol. 35 , no. 12 , pp. $13500-13513$, Dec. 2020. 